\title{
Bacteria Associated with Food
}

\section{Satya SS Narina*}

Department of Biology, Virginia State University, Petersburg, Virginia

*Corresponding Author: Satya SS Narina, Department of Biology, Virginia State

University, Petersburg, Virginia.
Received: February 18, 2020

Published: March 16, 2020

(C) All rights are reserved by Satya SS Narina.

\begin{abstract}
Bacteria are omnipresent prokaryotic organisms that were associated with food. The bacteria live in our intestine improve our metabolism to provide nutrition and protect from pathogen invasion to provide us health. There are bacteria that we consume every day along with our food to maintain internal homeostasis and these bacteria of alkaline nature help neutralise acids produced in the intestine. If harmful bacteria enter human system through cross-contamination or ingestion of spoiled foods might result in production of enterotoxins and toxi acids. These pathogenic bacteria cause foodborne illnesses, might be recoverable or lead to death in cases of severe infection. Use of antibiotics, prebiotics and probiotics, essential knowledge about the food safety and handling procedures during farm production, various stages of food supply and distribution until it reaches our table for consumption use may help in protecting humans from pathogenic bacteria.
\end{abstract}

Keywords: Bacteria; Campylobacters

\section{Introduction}

Bacteria associated with food might be harmful or beneficial. Bacterial association occurs with edible food by several ways and means of access which were regulated by temperature, moisture and acidity or alkalinity $(\mathrm{pH})$ of the environment inside human or outside in the consumable food. The edible food include raw vegetables or meat to cooked, pasteurised, processed, packed and frozen food materials. The bacteria can enter at any stage from field, animal shelter, slaughter house, processign industry, in storage, or from hand to hand due to improper sanitization. There are different kinds of bacteria requiring various levels of $\mathrm{pH}$, temperature and moisture and were classified accordingly (Table 1). The harmful pathogenic bacteria lead to food poisoning and in severe cases to death. The useful bacteria associated with food help in building up of gut microbia participating in metabolism.

Some of the health-promoting bacteria in the gut (probiotics) can elicit a multiplicity of inhibitory effects against pathogens. Hence, an increase in their numbers through fortification of in- digenous bifidobacteria/lactobacilli by using prebiotics should improve protection. There are a number of potential mechanisms for lactic acid bacteria to reduce intestinal infections. Firstly, metabolic endproducts such as acids excreted by these micro-organisms may lower the gut $\mathrm{pH}$ to levels below those at which pathogens are able to effectively compete. Many lactobacilli and bifidobacteria species are able to excrete natural antibiotics, which can have a broad spectrum of activity. Other mechanisms of useful bacteria include an improved immune stimulation, competition for nutrients and blocking of pathogen adhesion sites in the gut [1].

Foodpoisioning by harmful bacteria lead to foodborne illnesses which are most common in the modern world and were costly as well to prevent. Many intestinal pathogens like type 1 fimbriated Escherichia coli, Salmonella and Campylobacters utilise oligosaccharide receptor sites in the gut. Once established, they can then cause gastroenteritis through invasive and/or toxin forming properties. If the illness is not controlled by prescribed medicines might be fatal and lead to public health problem. 


\begin{tabular}{|c|c|c|}
\hline Name of the bacteria by category & Bacteria included in this group & Bacteria associated with food \\
\hline \multicolumn{3}{|l|}{ 1. Classification by pH: } \\
\hline Acedophile $(\mathrm{pH}<5.55)$ & Pathogenic E.coli, Salmonella typhi & Human intestine \\
\hline Neutrophiles $(\mathrm{pH}=7,5.5-8.5)$ & E.coli, Staphylococci, Salmonella & \\
\hline Alkaliphiles $(\mathrm{pH}>8)$ & Vibrio cholerae, Bacillus firmus & \\
\hline \multicolumn{3}{|l|}{ 2. Classification by temperature: } \\
\hline Thermophilic ( 41 to $122^{\circ} \mathrm{C}$ ) & Archaea & $\begin{array}{c}\text { decaying plant matter- peat bogs and } \\
\text { compost }\end{array}$ \\
\hline \multirow[t]{2}{*}{ Mesophilic (25 to $\left.40^{\circ} \mathrm{C}\right)$} & Micrococcaceae & Fresh produce \\
\hline & E.coli & Processed meat, poultry, and seafood \\
\hline Aerobic & Pseudomonadaceae, Neisseriaceae & Seafood, fresh meat, poultry, and eggs \\
\hline Facultative anaerobe & Enterobacteriaceae & $\begin{array}{l}\text { Fresh vegetables, meat, poultry, fish, and } \\
\text { eggs. }\end{array}$ \\
\hline Anaerobic & Clostridium botulinum & Deep sea flour, yogurt, Hydrothermal vents \\
\hline \multicolumn{3}{|l|}{ 4. Classification by mode of action: } \\
\hline \multirow[t]{5}{*}{$\begin{array}{l}\text { Harmful } \\
\text { - } \quad \text { Causing foodborne illness (Gibson., } \\
\text { et al., 2005) }\end{array}$} & Bacillus cereus & Cooked rice, meat \\
\hline & Salmonellae & Meat, poultry, eggs \\
\hline & Shigella spp. & Eggs, salads \\
\hline & Staphylococcus aureus & Ham, poultry, dairy products \\
\hline & Yersinia enterocolitica & Milk, poultry \\
\hline $\begin{array}{l}\text { Beneficial } \\
\text { - } \quad \text { Help in metabolism }\end{array}$ & Lactobacillus sp., Leuconostoc spp. & Yogurt \\
\hline \multirow[t]{5}{*}{ - $\quad$ Food and beverage industry } & Acetobactor sp., Bacillus sp., & Chocolate, vinegar \\
\hline & Glucanoacetobacter sp., & Coffee, beer \\
\hline & Arthrobacter sp., Brevibacterium sp., & Dairy, cheese, yogurt \\
\hline & Carnobacterium sp., and Corynebacterium & Cheese \\
\hline & Bifidobacterium sp., Lactobacillus sp. & Yogurt \\
\hline
\end{tabular}

Table 1: Classification of bacteria associated with food. 
Why is it necessary to know about bacteria associated with food?

The present day is loaded with too many physicians and too many manufacturers of medicines on which a normal human has no idea of what is good other than depending on doctors and pharmacists completely for their medication. Similarly, the food is not made by family like good olden days where entire family is dependent on mother's home cooked food. Therefore, people are completely dependant on fast food industries for their daily groceries of frozen microwaved food which has no waiting time and ready to eat if one has money to purchase to those cheaper quality and costly foods. This dependence on fast food packages, is making them store lots and lots of food in refrigerators for a long time which might let our microbial world into these valuable foods. Even home made food if not eaten for days, it might get spoiled by microbes too which is not advisable to eat after expiration. Therefore, complete dependence on stored food is not advisable in this modern society to continue a healthy life style.

Other incidences that might lead to food borne illnesses include 1) improper care of oneself towards quality atmosphere for taking quality food, 2) lack of supervision at a public facility of food preparation, supply chain, service or sale unit, 3) improper sanitization of cook who prepares food starting from purchasing necessary groceries at market, retrieving items from restaurent's storage facility without caring for their cleanliness. This may happen at fast food chains or in street foods 4) lack of time for people to keep an eye on what they consume out of their home or office refrigerators and 5) some customers choice of purchasing inferior quality foods which are at cheapest price due to their limited income 6) Purchase of vegetables, fruits or any food item in the grocery store from a dealer or middlemen who does not maintain a quality produce because it is a dependance for a long time due to their trust in certain farms and unaware of these postharvest food quality issues 7) Admixture of ingredients by sales or middlemen that were of low quality and less costly to gain net family income 8) Poor education standards of middle men who conduct lot of agricultural and food buisiness locallly 9) Lack of educated and experienced farmers in agriculture and horticulture sector in the modern world unlike ancient producers who gained lot of experience from their predecessors.

This indicates that high quantity of quality farm production is highly important for ever-increasing human population. The em- ployment or available jobs were very less due to the increasing population, indirectly preparing businessmen to feed their families. The best quality in any business always gain both income and fame, but a few know about this hard core secret while conducting business. Some business people always worried about their daily needs at the expense of their quality of service. Either in doctors office, farmers field or in a restaurent, whether in a highly developed country like USA or in an underdeveloped country like India, care for quality of service always accrue name and fame for several generations. Therefore, education of middlemen and commercial producers in maintaining minimal standards in quality of food produce is the most important step globally. This will help to earn national and international income with standard seal by replacing reuse policy with use and through policy. The use and through policy only saves lives from food borne illnesses, but might create environmental pollution if paper (plant or cellulose) based containers are not used.

\section{Harmful bacteria associated with food}

If the bacteria contaminated foods (frozen or home or restaurent made), are consumed accidentally without notice may result in food borne illness resulting in fever, stomach cramps, vomiting, dairrhea or might be fatal in rare incidences. The most common bacteria out of numerous microbia observed in our food items on regular basis are described below with the cause, spread, symptoms of foodborne illness and possible control measures (Source: www.foodsafety.gov/food-poisoning/bacteria).

\section{Campylobacter}

Most common bacteria in USA, lives in the intestinal tract of animals and human and spread through poor handling of contaminated foods from faecal matter of animals and humans. The campylobacter bacteria can be transmitted to humans through the consumption and processing of raw or undercooked meat (especially chicken, turkey and fowl), unpasteurised milk, untreated water and occasionally mushrooms and shellfish. it takes 3-5 days to appear symptoms in humans after infected by this bacteria, which include irritable bowel syndrome (IBS), reactive arthritis and Guillain-Barré syndrome might lead to serious nervous condition. The illness may stay from 2 to 10 days.

\section{Control measures}

Drink plenty of fluids and get rest. Safe handwashing using bacterial disinfectants is the only solution after using restrooms, handling animal and human faecal matter or handling spoiled food material. Always drink drink pasteurized milk and purified water. 


\section{Food handler tips}

People working in restaurents should not return to work until $48 \mathrm{hr}$ after symptoms have stopped to control the spread of the bacteria and infection. Cooking food thoroughly to $70-82^{\circ} \mathrm{C}$ for 2 minutes before eating.

\section{Salmonella}

Is the second most common bacteria that contaminates food and causes food poison illnesses "Salmonellosis" and enteric fever "typhoid". Meat (chicken, turkey, and fowl in particular), eggs, milk and seafood can all be contaminated with this bacteria. Handling and consuming raw contaminated foods, unwashed fruits and vegetables are a source of infection. It can take 12 to 72 hours to begin to experience symptoms such as diarrhoea, headaches, cramping, sickness, fever, might lead to typhoid and death.

\section{Control measures}

Vaccination is the only solution. Iron exposure may result in acculumation of Salmonella in intestine which might eb a risk factor for colorectal cancer and can be regulated by traditional chinese herbs [2]. Drink plenty of fluids and get rest. Avoid eating high risk foods like raw or lightly cooked eggs, under cooked ground beef or poultry and unpasteurized milk. Wash your hands frequently. As the infected humans continue to excrete bacteria through their faecus it is good to hand wash after infection as well to prevent spread of the bacteria and infection to other humans living in our proximity.

\section{Food handler tips}

Cooking food thorougly to $70-80^{\circ} \mathrm{C}$ for morethan 2 minutes before consuming even fresh food. Avoiding work till $48 \mathrm{hrs}$ after the symptoms stops.

\section{Staphylococcus aureus}

Fast growing bacteria and can produce toxins after contamination. Bacteria lives on hair, skin, noses, eye and throats and can spread through uncooked food such as sandwiches, salads, unpasterised milk and cheese products, puudings, pastries. It can tolerate salt and temperatures of 4 to $46^{\circ} \mathrm{C}$. Illness lives for a short period of time and symptoms appear from 1 to $6 \mathrm{hrs}$ after infestation, include vomiting, pain, diarrhea.

\section{Control measures}

Foods should be kept either above $45^{\circ} \mathrm{C}$ or below $4^{\circ} \mathrm{C}$ during storage so any staphylococci present will not be able to grow and produce enterotoxin [3].

\section{Food handler tips}

Adequate hand washing, personnel hygiene, kitchen sanitation, strict storing procedures at right temperature for specific (cold and hot) foods, and protecting displayed food with sneeze screens.

\section{Clostridium}

is a genus of gram positive bacteria that include human pathogens causing botulism (Clostridium botulinum), tetanus (Clostridium tetani) and other fatal infections (Clostridium sordellii, Clostridium perfringens). They are all obligate anaerobes capable of producing endospores. The normal, reproducing cells of Clostridium, called the vegetative form, are rod-shaped, which gives them their name. Clostridium species inhabit soils and the intestinal tract of animals, including humans.

\section{Clostridium perfringens}

Ever-present in nature and can be found as a normal component of decaying vegetation, marine sediment, the intestinal tract of humans and other vertebrates, insects, and soil. Uncooked meats, gravy, cured or pre-cooked foods can be contaminated with this bacteria, whose spores are harder to get rid of even at high temperatures. The bacteria prefers to grow in conditions with little or no oxygen. The bacteria produce a toxin in the gut. The symptoms appear within 8 to 24 hours resulting in abdominal cramping, nausea, fever and diarrhoea. It rarely causes vomiting or fever. The majority of outbreaks are associated with undercooked meats.

\section{Control}

Drink plenty of fluids, get rest or call doctor in severe cases. Use a food thermometer to make sure if the food is cooked to the right temperature of $140^{\circ} \mathrm{F}$ and above.

\section{Food handler tips}

Cooking and storing food at the right temperature of below $5^{\circ} \mathrm{C}$ and above $63^{\circ} \mathrm{C}$ is acceptable. A cooking temperature of $74^{\circ} \mathrm{C}$ is the only solution to kill the type A strain (CP-enterotoxin) of this bacteria.

\section{Clostridium botulinum (botulism)}

The most common source of this bacteria is processed canned meat and vegetables, meat and fish. Once humans are infected with the bacteria it can produce nerve affecting toxins that can impact vision, cause paralysis and even be fatal. All age groups are affected though incubation period to display illness and symptoms vary. Infants show the symptoms of lethargy, poor feeding, constipation, weak crying, poor muscle tone (floppy) within 30 days. Adults and 
children will show double vision, blurred vision, drooping eyelids, slurred speech, difficulty swallowing, dry mouth and muscle weakness.

\section{Control}

Need to see a doctor immediately.

Food handler tip

The most important thing to watch is use-by dates on your canned foods and to discard all swollen, gassy, or spoiled canned foods using a tightly closed double plastic bag.

\section{Escherichia coli (E. Coli)}

It spreads during slaughter through ground or tenderised meat, and from unpasteurized milk, soft cheeses, and fruit and vegetables and unpasteurized juices that have been affected through contaminated water. The symptoms appear between 1 - 10 days resulting in inflamation of intestines, sickness, fever, bloody diarrhoea, kidney damage and even death if affected by this bacteria.

\section{Control measure}

Safe food handling. Drink plenty of water, rest and call doctor if synmptoms include bloody diarrhoea and symptoms lasts for more than a week.

\section{Food handler tip}

Avoiding cross contamination, thorough cooking of meats and pasteurization of raw milk and juices is the only way of eliminating this bacreria. Thorough handwashing before, during and after preparing food, after dapering infants, after contact with pigs, goats or sheep and their food treats or their living environment.

\section{Listeria}

It spreads through the exposure of raw food or water to faecal matter and through the subsequent poor handling of contaminated food. Listeria can be rapidly destroyed by heat at $75^{\circ} \mathrm{C}$ during cooking, but is most commonly transferred through soft cheeses, uncooked eggs, and some types of processed meats (eg: cooked or sliced meats), smoked fish, cooked shellfish, soft mould-ripened cheeses, pate and pre-prepared sandwiches. Within 30 days of contamination by this bacteria results in symptoms of fever, headaches, septicaemia, meningitis and miscarriage. In invasive listeriosis, the bacteria invades blood and brain causing meningitis leading to death.

\section{Control measures}

Illness may last from days to weeks and adults at the age of 65 are at risk. Antibiotics are best besides preventive measures of drinking plenty of fluids, warm cooked foods of any kind.

\section{Food handler tips}

Avoid contact with foods after expiration of due time of consumption as well as stored food from $1-3^{\circ} \mathrm{C}$.

\section{Bacillus cereus}

It usually contaminates rice, leftovers, pasta, desserts, cheese, un [pasteurised milk, sauces, soups, and other prepared foods sat out for along time at room temperature. It results in symptoms of diarrhea (6 -15hr), abdominal cramps, nausea, vomiting (30 - 6hr). This baceria is found in foods that come in contact with soil like cereals and vegetables.

\section{Control}

Drink plenty of fluids to prevent dehydration. If foods require storage for longer than 2 hours, keep hot foods at temperature of more than $140^{\circ} \mathrm{F}$ and cold foods at temperatures of more than $40^{\circ} \mathrm{F}$. Store cooked food in wide, shallow container and refrigerate immedately after transfer to a stroage container.

\section{Food handler tip}

Because these bacteria are highly salt and heat resistant, it is good reheat each time before consuming food to avoid cross contamination as well as contamination during long hours of cooling period given after cooking at relatively high temperatures to kill the bacteria.

\section{Shigella}

Only fresh foods like salads, raw vegetables are prone to shigella bacterial contamination. Within 3 days, the symptoms like fever, nausea, vomiting diarrhea appear and last for not more than a week. In severe case it might lead to painful eyes, swelling of the joints and pain during urination imitating Reiters syndrome.

\section{Food handler tip}

Sanitation in the kitchen, personal hygiene by regular handwashing would help preventing the spread of the bacterial contamination to food.

\section{Vibrio parahaemolyticus}

It is less known as a food poisioning bacteria. It affects human health directly through consumption of contaminated food, open wounds or swimming in contaminated waters. This is most commonly found in seafood, in particular oysters, clams and other shellfish, but also tuna, sardines, mackerel, squid and crab. It is also found in seawater contaminated by the faeces of infected sea creatures. The symptoms include diarrhoea, fever, septic shock, sudden chills, skin lesions and blistering skin wounds. 


\section{Control measures}

Contact doctor immediately after infection is noticed. Cooked seafood is always advisable. Wear cloths and shoes that protect cuts or scrapes from salt or sea water.

Food handler tip

Avoiding cross contamination between cooked and raw sea foods including fish and shellfish. Boiling, steam cooking for 3 - 10 minutes as well as deep frying to minimum of $191^{\circ} \mathrm{C}$ is another important way to avoid this type of food poisoning in sea foods.

Major group of bacteria contaminating food [4]:

1. Pseudomonadaceae: These nonspore-forming Gram-negative rods are psychrophilic in nature, aerobic, and oxidase positive. The representative genera of this family of bacteria include Xanthomonas and Pseudomonas. Pseudomonads are well-known major spoilage microorganisms in seafood, fresh meat, poultry, and eggs.

2. Neisseriaceae: These are gram-negative rods, nonspore forming, aerobic, and catalase positive. The representative genera include Acinetobacter (oxidase negative) and Moraxella (oxidase positive). Some strains of Acinetobacter are psychrophilic. They also infect foods like that of pseudomonas.

3. Enterobacteriaceae: These are gram-negative rods, facultatively anaerobic, fermentative, mesophilic, nonspore forming, oxidase negative, and catalase positive. The representative genera include Escherichia, Erwinia, Enterobacter, Citrobacter, Serratia, and Proteus. These bacteria are usually involved in the spoilage of fresh vegetables, meat, poultry, fish, and eggs.

4. Micrococcaceae: These are gram-positive and spherical, with a catalase positivity, and mesophilic in nature. The two main representative genera are Micrococcus and Staphylococcus. They are commonly involved in the spoilage of fresh produce and processed meat, poultry, and seafood.

5. Lactic-acid bacteria: The representative genera are Lactobacillus, Leuconostoc, Streptococci, Lactococcus, Enterococci, and others. All members of this group are gram-positive, do not produce catalase, microaerophilic, are sometimes facultatively anaerobic in nature, and fermentative. The growth of these bacteria spoil fresh foods, such as meats, vegetable salads, and fluid milk.

6. Coryneforms: The representative genera are Corynebacterium and Brevibacterium. These microorganisms are mostly not so important for food contamination but play a vital role in spoilage of cheese. Both of these are gram-positive and catalase positive. Their sources of contamination are usually soil, animals, or humans.

\section{Outbreaks}

Food spoilage leads to chanegs in flavor, odor, taste and other qualities of food due to fermentation, putrefaction and rancidity caused by various harmful bacteria inhabiting improperly stored food, manufactured or prcessed food (Table 2). This results in production of organic acids, alcohols, gases from fermentation of sugars when microbes acted on carbohydrates, which has industrial value. Protein rich foods if spoiled by proteolytic enzymes produced by microbia, might lead to production of H2S, amino acids, ammonia, amines giving off flavours. When lipids are attached by microbes, gives unpleasant smell due to production of fatty acid and glycerol by the action of lypolytic enzymes under microbial spoilage. Therefore, when a food is stored or consumed, if it gives anything off flavor or taste, it is good to avoid that food to save our life and communicating the same immediately to the public health department, food safety units and FDA for further action to save the public and publication of the information on outbreaks that might occur at various steps in food chain. An example of outbreak was provided as a reference to inform the value of the quality of food taken inside our system.

\begin{tabular}{|l|c|c|}
\hline Food item & $\begin{array}{c}\text { Changes due } \\
\text { to spoilage }\end{array}$ & $\begin{array}{c}\text { Bacteria involved in food } \\
\text { spoilage }\end{array}$ \\
\hline Bread & Ropy & Bacillus subtilis \\
\hline Fresh meat & Putrefaction & Clostridium \\
\hline Fish & Discolouration & Flavobacterium \\
\hline $\begin{array}{l}\text { Concentrated } \\
\text { juices }\end{array}$ & Off flavor & Acetobacter, Lactobacillus \\
\hline Milk/Cream & Ropiness & $\begin{array}{c}\text { Enterobacter, Lactobacillus, } \\
\text { Streptococcus, Bacillus }\end{array}$ \\
\hline & $\begin{array}{c}\text { Decomposition } \\
\text { of fats }\end{array}$ & Bacillus, Clostridium \\
\hline & Flavor changes & Lactobacillus, Streptococcus \\
\hline
\end{tabular}

Table 2: Changes in the food items due to spoilage by bacteria. 
An outbreak of staphylococcal food poisoning resulted in vomiting, diarrhea and dizziness due to illness of 31 individuals was reported within 30 minutes after eating the meal containing chicken pancake, rice, beans, tomato sauce and mashed chickpeas. The chicken pancake was observed containing large numbers of enterotoxigenic staphylococci strains A, B and D. The source of this contamination was revealed as improper sanitization of food handler finger nails, nasal cavity and throat [3]. Several species of Staphylococcus bacteria were recivered from sheep milk that were known to produce enterotoxins. Not only bacteria various other microbes like fungi and virus might attack the food or food can get spoiled due to undesirable air, light, oxygen and temperature conditions causing catalysis giving off flavors during storage leading to outbreaks if the material is purchased from a grocery store by a living community [4].

Now you know what to avoid in terms of food safety and let us discuss briefly about useful bacteria associated with food to be healthy.

\section{Useful bacteria associated with food}

There are many uses from bacteria in meeting with our daily metabolic needs by building gut microbia in both children and adults [2] and making several food products on regular basis by our food and beverage industries (www.fao.org). The human gut mucosa, consists of epithelial cells, lamia propria, and the muscularis mucosae, is colonized by $10^{14}$ microbes, ten times more than the human cells were present. Among these, bacteria play an important role in human health to supply essential nutrients, syntheise vitmain $\mathrm{K}$, digestion of cellulose, promoting angiogenesis and enteric nerve functions. Any change in the gut bacteria composition due to use of antibiotics, illness, stress, aging, bad dietary habits and lifestyle may be harmful [2]. Most commonly used bacteria were Acetobactor sp., Bacillus sp., and Glucanoacetobacter sp., in making chocolate, vinegar, coffee, beer, Arthrobacter sp., Brevibacterium sp., Carnobacterium sp., and Corynebacterium sp., in making cheese, Bifidobacterium sp., Lactobacillus sp., in making yougurt and other dairy products of our daily use food products [4].

The main gut bacterial phyla, in the order of numerical importance, are Firmicutes, Bacteroidetes, Actinobacteria, Proteobacteria, Verrucomicrobia and Fusobacteria. Bacteroidetes and Firmicutes are the main bacteria in the metabolism of undigested food rem- nants. They help to digest dietary fiber and polyphenols by a complex metabolic energy-harvesting mechanism, which is based on crossfeeding and co-metabolism. In return, commensal bacteria take advantage of the protective and nutrient-rich environment of the host. The commensal bacteria contribute to the host defense by regulating the homeostasis of the host immune system. This can be achieved by reduction in intestinal $\mathrm{pH}$, producing toxic substances, or lactate and short chain fatty acids to inhibit pathogenic bacteria. Firmicutes are gram-positive bacteria with a low $\mathrm{G}+\mathrm{C}$ content, including the large class of Clostridia and the lactic acid bacteria, while Actinobacteria are gram-positive bacteria with a high $\mathrm{G}+\mathrm{C}$ content, including Colinsella and Bifidobacterium spp. Lactobacillus and Leuconostoc spp. are the main lactic acid bacteria found in the human intestine. Bifidobacterium spp. is the predominant bacteria found among the first colonizers of new borns, and persists at a low level in adults. These bacteria can be aquired from digested food. For example, infants fed with breast milk had higher levels of Bifidobacteria spp., while infants fed with formula had higher levels of Bacteroides spp., Clostridium coccoides and Lactobacillus spp.,[2].

Food fermentation is an ancient technology, disseminated worldwide, which harness microorganisms and their enzymes to improve and diversify the human diet. Fermented foods (vegetables, animal products, beverages) represent 10 to $40 \%$ of the global diet, and represent a cultural and gastronomic heritage of high value. Fermentation-either indigenous or after addition of starter cultures-brings many benefits, including (1) enhanced food stability and storage, decreased food losses; (2) enhanced food safety by inhibition of pathogens; (3) improved sensory properties; and (4) improved nutritional value. A better knowledge of microbes and fermentation at the molecular level is required to support and develop the production of sustainable fermented foods with high nutritional characteristics [5].

\section{Conclusion}

When compared, benefits of bacteria are dominating over their harmful effects associated with food spoliage and associated food borne illnesses. Food safety is assured as long one has control over the sanitization and in avoiding cross-contamination before, during, and after food preparation. For example, recent findings of Listeria monocytogenes (LM) survival on factory floor in specific locations were a proof to show the evidence of no detection of LM on food contact surfaces despite the sanitization treatments of executed protocols. The LM was detected on non-food contact surfaces only in a dessert processing factory [6]. Likewise, it is good to scan the location of 
most common microbial load and its prior sanitization is the key for food safety. Well laid procedures that adhare to strong santization rules while cooking, handling and storage of food materials is the most important step in any kitchen at home or outside to avoid the major illnesses due to cross contamination of food products. Maintaining internal homeostais by building up of useful gut microbia is a potential requirement at all ages to avoid major risks of diabetes, obesity, cancer, autism, arthritis and ulcers. Several studies related to gut microbia, effect of prebiotics and probiotics were discussed by eminent faculty at cellular and molecular level of understanding the concept and the role of bacteria in human health [7].

\section{Bibliography}

1. Gibson GR., et al. "Rastall Prebiotics and resistance to gastrointestinal infections". British Journal of Nutrition 93.1 (2005): 31-34.

2. Zhang YJ., et al. "Impacts of gut bacteria on human health and diseases". International Journal of Molecular Sciences 16.4 (2015): 7493-7519.

3. Luiz Simeão do Carmo., et al. "An Outbreak of Staphylococcal Food Poisoning in the Municipality of Passos, Mg, Brazil". Braizilian Archives of Biology and Technology, An International Journal 46.4 (2003): 581-586.

4. Majumdar A., et al. "Chapter 5: Microbial contamination and food degradation. Handbook of food bioengineering". Elsevier publication (2017): 109-148.

5. Talon R and Zagorec M. "Special Issue: Beneficial Microorganisms for Food Manufacturing-Fermented and Biopreserved Foods and Beverages". Microorganisms 5.4 (2017): 71.

6. Campdepadrósa M., et al. "Effectiveness of two sanitation procedures for decreasing the microbial contamination levels (including Listeria monocytogenes) on food contact and nonfood contact surfaces in a dessert-processing factory". Food Control 23 (2012): 26-31.

7. Mohajeri MH., et al. "The role of the microbiome for human health: from basic science to clinical applications". European Journal of Nutrition 57.1 (2018): 1-14.

\section{Assets from publication with us}

- Prompt Acknowledgement after receiving the article

- Thorough Double blinded peer review

- Rapid Publication

- Issue of Publication Certificate

- High visibility of your Published work

Website: https://www.actascientific.com/

Submit Article: https://www.actascientific.com/submission.php

Email us: editor@actascientific.com

Contact us: +919182824667 